\title{
Risks and Barriers Associated with Mobile Money Transactions in Tanzania
}

\author{
Gwahula Raphael \\ Department of Accounting and Finance, The Open University of Tanzania, P.O. Box \\ 23409, Dar Es Salaam, Tanzania
}

Tel: 255-222-667-450 E-mail: gwahulagr@gmail.com

Received: Sep. 26, 2016 Accepted: Sep. 29, 2016 Published: December 3, 2016

doi:10.5296/bms.v7i2.10069 URL: http://dx.doi.org/10.5296/bms.v7i2.10069

\begin{abstract}
The study was about Risks and Barriers Associated with Mobile Money Transactions in Tanzania. The focal point of the study was to spot and reveal risks and barriers experienced by mobile money users in mobile money transactions (MMT) and the frequencies of their incidences. It also assesses the level of users' understanding and how they can avoid themselves from barriers and risks exposing environment. The research was based on primary data which was collected in a survey done in Ilala district through questionnaires. Data analysis was based on descriptive statistics and interpretation based on positivist assumptions in which the results were quantitative and independent from the researcher. The research findings reveal that while the most likely experienced risks are a loss of password, fake transaction request, and fake money, the barriers are a poor network, agent lack liquidity, and lack of identity card. However, the rate of incidence of risks and barriers in MMT are moderates. The study, therefore, recommend that the regulatory authority should guarantee the security of mobile money users by improving MMT rules and regulations, they should also stress mobile companies to create MMT awareness in risks, rules and regulations to mobile money users to encourage their participation in this industry and finally the mobile company should improve mobile money network infrastructures and application platforms.
\end{abstract}

Keywords: Risk, Barrier, Transaction, Mobile money 


\section{Introduction}

\subsection{Background to the Problem}

Mobile payments are on the rise, and it is argued that the magnitude of using mobile payments is higher in developing countries compared to developed ones (Nielsen, 2014). According to GSMA (2014), the number of active mobile money accounts increased by $64 \%$ from 2012 to 2013 worldwide. The 2015 report by GSMA (2015) again revealed that the number of mobile money users continues to grow, as of December 2014 it was observed the increment of $41 \%$ active mobile money accounts worldwide, with more than 100 million active accounts compared to 73 million in December 2013. Penicaus and Katakam (2013) argued that at the end of 2013 there were 219 mobile money services in 84 countries of the world compared to 179 services in 75 countries at the end of 2012. In 2014 GSMA (2015) witnessed 255 mobile money services in 89 countries; this is equivalent to $61 \%$ of world's developing market. They further evidence that Sub-Saharan African is leading to employing mobile money service with $51.7 \%$ of the unbanked, followed by south Asia, $16.1 \%$, Latin American \& Caribbean, 13.3\%, East Asia and Pacific, 11.5\%, Middle East \& North Africa $6.0 \%$ and the last is Europe and Central Asia with $1.4 \%$.

African countries, specifically Sub-Saharan have showed a great and rapid advancement in mobile money services. In 2012, there were only four countries in which mobile money account exceeded bank account but it increased by 55.6\% to the end of 2013. Nine countries Cameroun, the Democratic Republic of Congo, Gabon, Kenya, Madagascar, Tanzania, Uganda, Zambia and Zimbabwe evidenced to have more mobile money accounts than bank accounts (GSMA, 2013). As of December 2014, over 50\% of MNOs in Sub-Sahara Africa have already launched mobile money services. However, in 2014 there was no significant increment of MMS in Sub-Sahara Africa compared to Latin American and Caribbean but a rank still shows that Sub-Sahara Africa accounts for the majority of live service globally (53\%), GSMA (2014). ITU (2013) revealed that fewer numbers of people in developing countries, particularly in Africa, hold formal bank account; it is estimated $41 \%$ of the developing countries and $20 \%$ of adult Africans, respectively. Several factors account to this observation, but the distance from where the bank is located to where the rural majority live and the poor transport systems are experienced to be major contributing factors.

Lack of having formal bank account contributing to increasing of informal methods of transferring money and cash based transactions which is very risky and expensive (World Bank report, 2012). Therefore, people were looking for the alternative secure methods of money transactions which can also cut off costs. The innovation of mobile technology application and rapid spread of mobile phones make the use of mobile money transactions more appealing. Villasener (2013) argues that although there is a growing trend of mobile money (MM) presence in Latin America, East Asia and South Asia, the Sub-Sahara Africa, in particular, East Africa is experienced to lead the activity. In Tanzania, the first mobile financial service was accessed in 2008. The mobile financial service experienced exponential increases; up to 2013 about $43 \%$ of adult populations were actively using this service. The 
services have greatly enabled unbanked population especially rural majority to have convenient access to payment services (Di Castri and Givani, 2014). Economides and Jeziorski (2015) released recent statistics that $35 \%$ of household in Tanzania have mobile money accounts. While $32 \%$ of households are exclusive users of mobile money account, only $2 \%$ have active bank accounts. The increase of mobile financial services has greatly been catalyzed by the telecommunication industry speedup, and obviously the speedup is contributed by the advancement of Science, Technology and Innovation (STI). Materu-Behitsa and Diyamett (2010) evidenced that Tanzania's telecommunications sector advanced from $20.5 \%$ in 2008 to $21.9 \%$ growth in 2009. Cited Tanzania Telecommunication Authority (TCRA) the researchers stressed that the number of licensed telecommunication operators increased from 5 to 62 in 2009. The number of mobile SIM cards sold increased from 3.5 million to 17.5 million. Tanzania has more than 11 million active mobile money accounts and approximately 153,369 agents in December 2013. This counted from 34\% of the household has at least one mobile money user and $33 \%$ of the households have at least one registered mobile money user (Di Castri \& Givani, 2014).

However, every change comes with its implications; the rapid increase of mobile financial services experiences the complexity. According to GESCI (2010), the development of STI accelerates fundamental changes in the society. The change is marked by a complex and multi-faceted challenges and increasing uncertainties that the past approach to strategy and problem-solving is no longer sufficient for dealing with the reality of the modern world. Despite the number of efforts established by both TCRA and Bank of Tanzania (BoT) to regulate and embrace financial inclusion as a public policy objective, using the legal and regulatory framework for mobile payments, the dynamic nature of mobile applications lead to mobile money transactions uncertainty in Tanzania. Therefore, this period is possessed with both change in mobile phone and the applications, it is not surprising that a substantial amount of attention should not only be put exactly on the benefits but also warn of its dangers. Protection of the mobile system can prevent data tampering from hackers and ensure the security of consumers' rights.

\subsection{Objective and Significance of the Study}

This study intended to investigate the risks, barriers involved and level of literacy in mobile money transactions in Tanzania. The findings, evaluations and recommendations from the study are useful to the Tanzanian telecommunications and financial regulatory authorities. It is also useful to financial institutions, especially mobile companies and banks which offer MMS, as it gives a clear picture about the risks and barriers in mobile financial services. Therefore, it has a contribution in decision making as well the area of policy and regulatory framework. 


\section{Literature Review}

\subsection{Theoretical Literature Review}

Three theories describe various means through which Mobile Money Transaction are operated. The routine activities theory which was introduced by Cohen and Felson (1979) and it was well explained by Branic (2014) scrutinizing the probability of crimes to occur with the underlying assumptions that the likelihood of occurrences of crimes to occur depends on the intersection of different social actors in space and time. The social intersected actors to determine the incidence of and distribution of criminal behaviors are motivated offenders, suitable targets and the absences of capable guardians. Another theory in this study is explained by Ellu and Heidgger as it cited by Feinberg (1991) is substantive theory of technology. It has the assumption that technology can either be positive or negative depending on the context in which it is operated, society may decides to use it in either way of the two. Therefore, it is our culture that determines the usefulness or harmfulness of the technology. A third theory is social construction of technology as explained by D'orsay (2014) that the understanding, significance, and meaning of technology is developed by social coordination and interaction but not individuals. Therefore, for the purpose of this study a social construction theory of technology was adopted herein. This theory concentrates on society that can shape the use or misuse of certain technology. This means technology is socially constructed, and it is typically identical to the process of mobile money transactions. Social interaction among social groups and different actors shape the technology, and there is no 'best' or 'worst' technology, but it is a society that decides to adopt or reject a certain technology according to their needs. Therefore, the society may shape the way MMT is operated and hence dedicate the outcomes; they can then determine the mitigation of the uncertainty by setting perfect policy, rules and regulations.

\subsection{Empirical Literature Review}

A study done by Chatain et al. (2011) about financial crimes on mobile money aimed at contributing and providing guidance on policy, regulatory and the supervisory on anti-money laundering and combating financial terrorism (AML/CFT) of mobile money. In the documentary review and the survey done globally it was revealed that there is a substantial supportive opportunity, but the abuse can risk mobile money to support financial inclusion. In the study, the author categorizes four major risks associated with mobile money which are: anonymity, elusiveness, rapidity, and poor oversight. The first three risks are inherited in the operation of the mobile money business model; poor oversight creates conditions that increase the likelihood of emerging of other three risks. The authors then emphasizes that the mobile money enabling environment must entail effective regulating and supervising of any potential risk.

Merritt (2010) has different views about mobile money risks. In the study concerning with development in mobile money transfers, based on observation and documentary review done in the USA revealed that the risks inherited in retails payments systems also present in mobile 
money payment, they include money laundering, lack of privacy and security, lack of consumer protection, credit risk, and liquidity risk. Realini (2011) in the survey conducted in different countries in Africa and Asia expresses the fear that risks and security may pose new challenges to the development of MM. The author argued that there is MM risks and security which all associated with data security, financial fraud and money laundering that are to be managed. In order to manage them, mobile financial services providers have to know about identities of users, the origin, and destination of funds, and the authenticity to conduct transactions with those funds.

Harries et al. (2013) in the surveys and documentary review conducted the study about private and security concerns associated with MM in Africa. Results from this study contrast that of Realini which need the exposure of the user identification. The researcher here argues that the needs of not conducting MMT anonymously and the mandated by regulations to maintain consumers record for some years, limit the privacy protection which leaves personal information susceptible to theft or leakage, ultimately damaging user's trust and limiting adoption and use of MM. The researcher again argues that mobile phones link directly to financial accounts and rich data sets, it increase the desirability to hackers. Smartphone is susceptible to the same danger that personal computer (PC) can face viruses, worms, and botnets that may create an environment for a user to lose not only personal information but also money and being in danger to other forms of crime through exposure via the mobile phone. Wamuyu (2014) also conducted a survey about mobile money usage and found that fraud and making a transaction to the wrong number as the major risking factors of mobile money services in Kenya. A similar survey done by Senso and Venkatakrishnan (2013) at Singida about challenges of mobile money transfer services, declared nearly the same results. The researchers here observed that fraud, a swap of SIM card, fake money, fake transaction request text message, PIN leakage and unfaithful workers are among the risk associated with MMS in Tanzania facing both mobile money customers and agents.

However, of the all exposed risk of mobile money services, most African countries do not have proper regulations and Acts that can safeguard the operations. Ally (2014), in the study about 'the prospects and legal challenges posed by mobile money in Tanzania', showed a concern of legal and security issues in association with mobile money. The author reviewed several documents and found that the nature of transactions needs legal and regulatory governance, a framework to determine important legality aspects to address the relationship between the financial institutions and consumers. A researcher pointed out that the mobile money transaction in Tanzania is not legally safeguarded. Therefore, it can expose Tanzanian to money laundering and terrorism-related activities in which the Anti-money Laundering Act of 2006 does not include cyber-related acts as its part. Mshana (2015) conducted a survey in Tanzania and came up with the same views. The author actually concurs with the previous researcher that there is no special Act which has been established to combat data related crime activities. The regulatory authority does not have any clear Act which protects users against cyber crimes. In supporting this Villasoner (2013) in his survey and documentary reviewed about mobile money and digital inclusion argues that technology alone is not enough to serve 
all unbanked population without regulations. Regulation is the biggest factor in determining quick move of the unbanked population to a fully digital and financial inclusions. The researcher again pointed that the MM is sometimes exploited with crime activity, therefore, the regulations to fight crime should not impede MM services, instead should adapt the traditional financial systems of combating crime to MM industry in appropriate ways.

Mobile money risks go hand in hand with barriers. An in-depth interview conducted by Chipchase et al (2011) reveals that in Afghanistan numerous barriers face the growth of MM. The barriers identified are illiteracy, some people do not own mobile phone, agent lack of liquidity, legal document transactions authentication, and agent flat commissions for every transaction.

Related studies conducted in Ghana and the other in Tanzania come with different results. Dzokoto and Appiah (2012) interviewed a number of people in Accra and identified several barriers facing MMT which are the persisting government regulations are not openly encouraging the mobile financial services inclusion and the educational barriers. InterMedia (2013) interviewed a number of people in different areas in Tanzania and revealed that the most limiting factors of mobile money users in Tanzania are: mobile users are not aware of mobile money service (13\%), some have insufficient understanding of mobile money services $(12 \%)$ and the low liquidity of the mobile money service agents.

\subsection{Conceptual Framework}

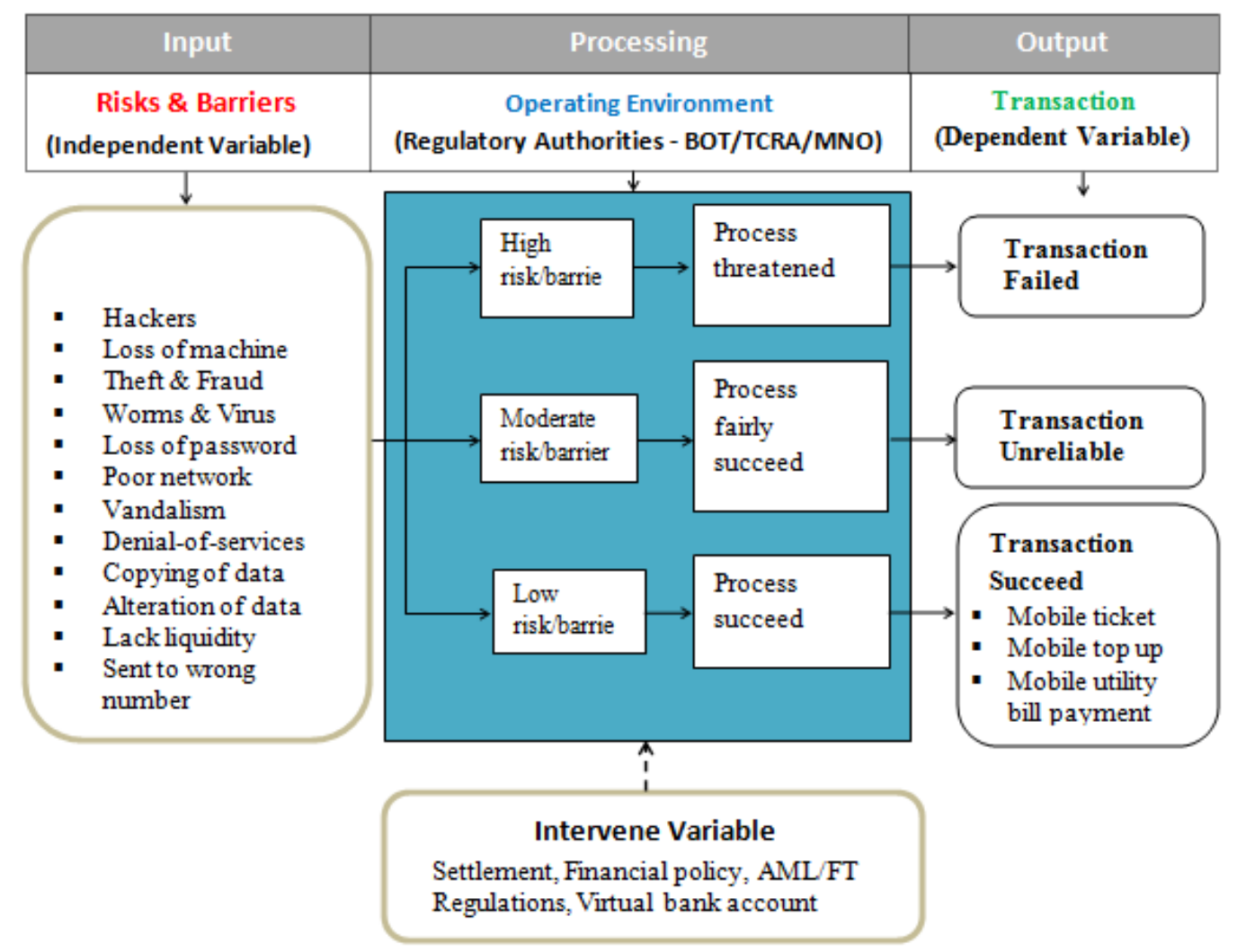

Figure 1. Mobile Money Transaction Variables Relationship 


\subsubsection{Discussion of the Conceptual Framework}

The scenario above depicts three variables: risk and barrier which are independent variables, a transaction which is dependent variables and financial institutions regulations and policies which are intermediate or intervening variables. Under this approach, the non-bank relationship is established between customer and mobile network operators (MNO). This mode overcomes the problems that prevent people from establishing a formal bank account. In this model, the customer's money is recorded in the virtual account on the server of the non-bank entity, in which customers can make money transfer, deposit and utility bill payments. Customer sends a transaction request to the MNO and then the MNO requests the access from the virtual account in the non-bank entity database (DB). The success of the transaction depends on the strength of network and authentication of the MNO request accessibility of the DB. The transaction might also be vulnerable to cyber scam; therefore a high level of security is required. Thus, presence or absence of risks and barriers and the financial regulations and policy set by the authorities, determine the victory of occurrence of the transaction. That means, in high risks and barriers with no regularizations the transaction normally fails while the transaction succeeds only if there are perfect regularizations or there are no risks and barriers in the operating environment.

\section{Methodology}

The study assumed a positivist attitude; it was possible because the study focused on factual information. The approach was also influenced by the fact that the subjects being investigated were independent of the researcher believes and views (Mokalane, 2013). In the positivist paradigm, the object of the study is independent of researchers; knowledge is discovered and verified through direct observations or measurements of phenomena (Krauss, 2005 cited by Mokalane, 2013). Therefore, this study was empirical and systematic, preferring precise quantitative data and often used survey and statistics hence the epistemological position of positivist was adopted.

A survey method of collecting data was employed; it is preferred here because of nature of the study itself which is the deductive approach (Magigi, 2015).

A sample from the adult population of 827397 in which 401916 were male and 425481 female of Ilala municipality (NBS, 2012) was extracted. The sample was then divided into two groups: the primary group was the MM services clients and the MM retail agents. The MM services clients are direct consumers of MM services, believed to give proper and primary information and the agents are the ones who provide MM service on behalf of MNO, they also give information concerning MMT.

A combination of simple random and purpose sampling were applied. Simple random sampling was deployed to respond questionnaires whereby adult MM consumers were selected to explore the information. Here, no standard approach was used, a researcher just chosen off any mobile user at the forefront, it ensure an equal and unsystematic likelihood of getting respondents. This sampling was opted because it gves an equal chance or probability 
of selecting each unit from the population being studies for inclusion in the sample. Purposive sampling was then adopted to reach MM users with particular characteristics of a population which is of interest; it allowed a researcher to use his own judgment to select cases that enabled to meet the objectives. It focused on MM retail agents which best enabled to answer research questions. A total of 100 respondents were approached, comprised of 85 consumers and 15 retail agents. The sample size considered residents, students, businessmen, government and non-government officials.

The questionnaire techniques were primary preferred methods of data collection as most of the data $(98 \%)$ were collected through this method. Here, structured questionnaires were distributed to selected mobile money users in different areas of Ilala district. Where there were some reasons that hinder effective questionnaire responses, the interviews techniques were used.

\section{Findings and Discussions}

\subsection{Risks Faced by Mobile Money Users}

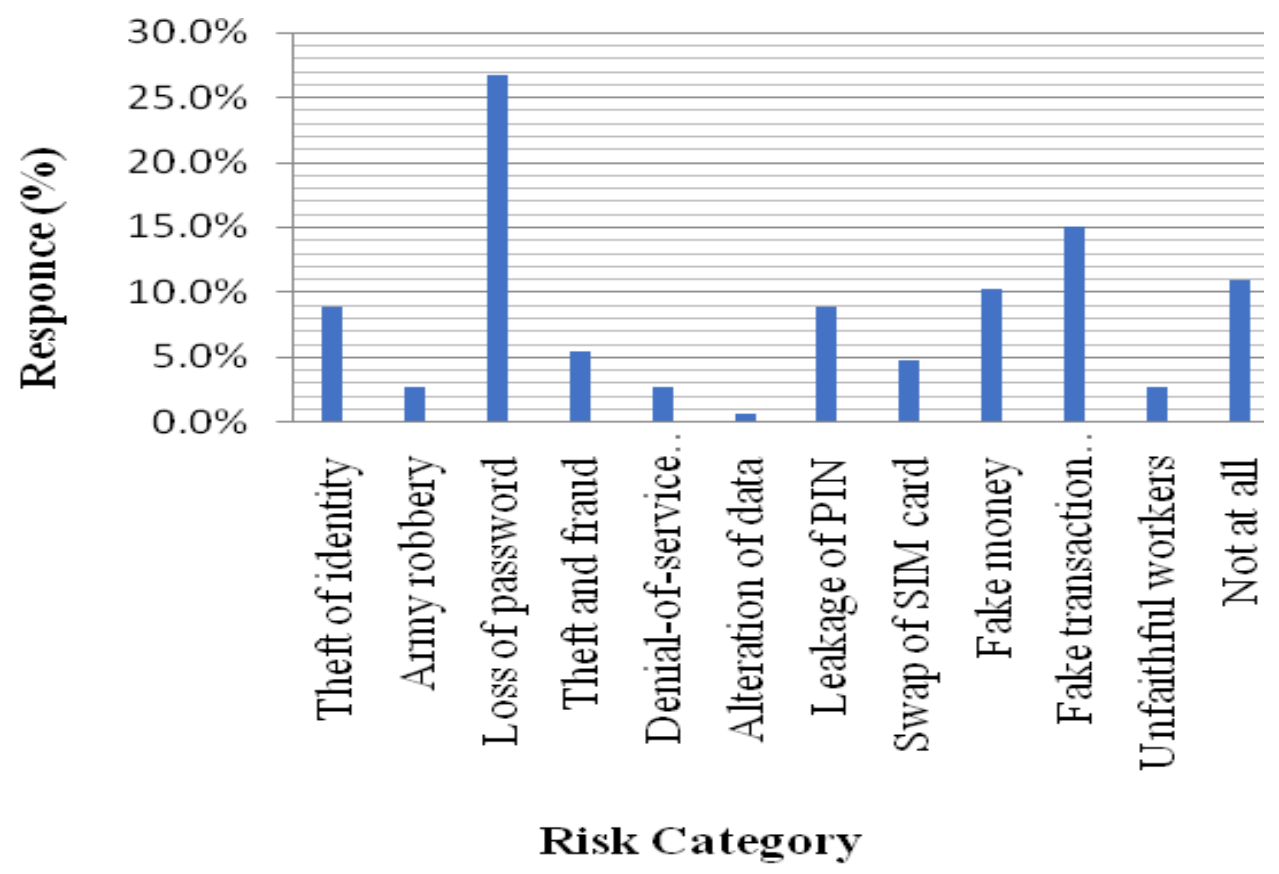

Figure 2. Respondent views on risks faced in MMT

A multiple selections questions in the first section was used to identify kind of risks faced by mobile money users. The result was set in the figure 2 above and it shows that a significant of nearly $27 \%$ of respondents face the risk of losing password of accessing their mobile money system application. The second largest risk which mobile money users faced was fake transaction request $(15.1 \%)$ followed by provision of fake money $(10.3 \%)$. Therefore, the results evidence that the users face risks in mobile money transactions, most of the risks are fraudulent risks caused by dishonest people. 
As noted in the literature review above the outcome from this study concur with the results obtained by Senso and Venkatakrishnan (2013) in Singida, Tanzania. Consequently, regardless of geographical location, time and change in technology risks of MMT in Tanzania are the same.

Table 1. Respondents Views on the Frequency of Facing Risk in MMT

\begin{tabular}{|c|c|c|c|c|}
\hline \multicolumn{2}{|c|}{ Category } & \multirow{2}{*}{$\begin{array}{r}\text { Frequency } \\
39\end{array}$} & \multirow{2}{*}{$\begin{array}{r}\text { Percent (\%) } \\
39.0\end{array}$} & \multirow{2}{*}{$\begin{array}{r}\text { Valid Percent (\%) } \\
39.8\end{array}$} \\
\hline Valid & Not at all & & & \\
\hline & Sometimes & 51 & 51.0 & 52.0 \\
\hline & Frequently & 8 & 8.0 & 8.2 \\
\hline & Total & 98 & 98.0 & 100.0 \\
\hline Missing & $\begin{array}{l}\text { Not } \\
\text { answered }\end{array}$ & 2 & 2.0 & \\
\hline Total & & 100 & 100.0 & \\
\hline
\end{tabular}

The next question in this section sought to establish the frequency in which mobile money user lose money through MMT. The question dictated the respondent to choose only one response among of three (not at all, sometimes, and frequently). The results displayed in Table 1 above show that while slightly above a half of the respondents (52\%) faced the incidence risk of losing some money through MMS is moderate, 39\% did not face this incidence at all and only $8.2 \%$ experienced this risk often. Therefore, there is no high rate of risk experienced in MMT as the evidence show that it is average. These results imply that most people engage in the MMT because there is no high frequency of risk of losing money faced by users. Thus, people are confident that the service is secure and their money will be safe. The result here with that of (Huwaiju, 2013) who argued that MMT provides a secure platform in which it is not only used as a medium for receiving and sending money but also used as money storage medium as the informal saving channel are much less secure. Therefore, the risk of cash getting lost or stolen is minimized as there is no need to carry cash. 


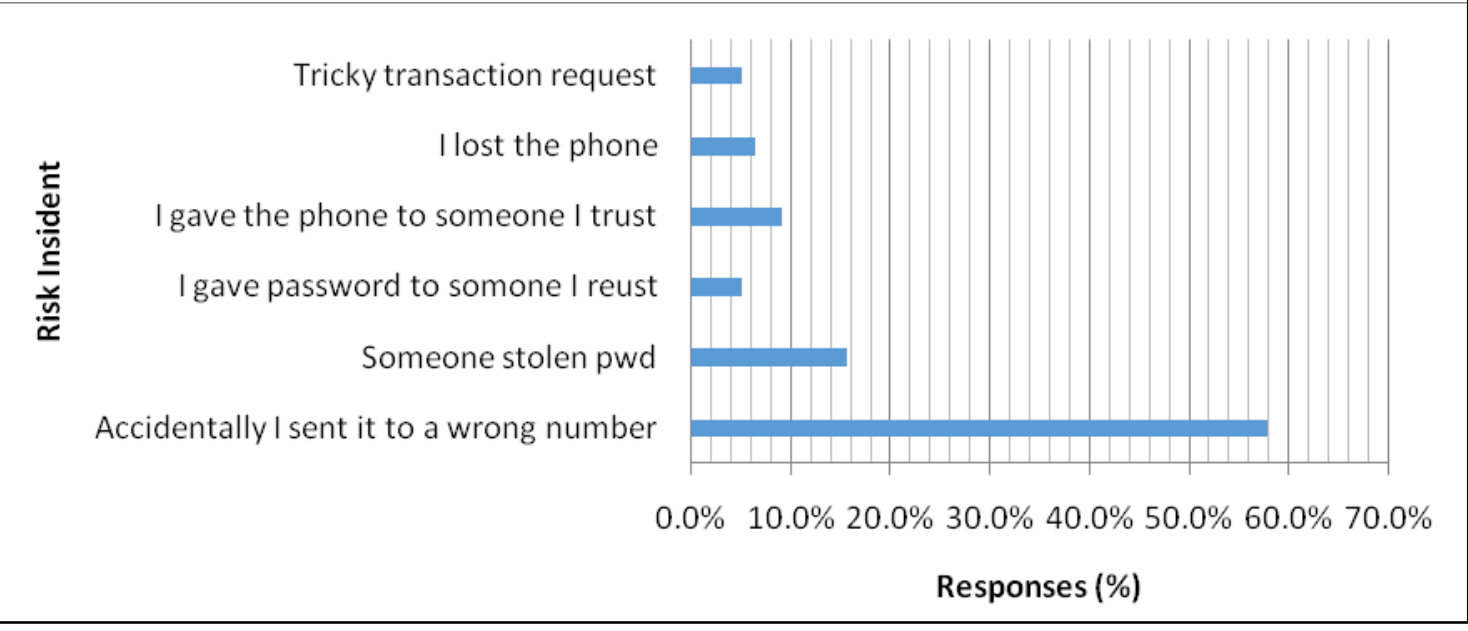

Figure 3. Respondents Views on the Incident that made them Lost Some Money

Another question sought to establish an incident that leads the money to be lost through MMT. This was a multiple response questions that allowed respondents to choose more than one responses. It is clearly showed that majority of respondents, nearly $60 \%$ of respondents faced the incident of sending money to the wrong number, while slightly above $16 \%$ declared the loss of password was the incident faced them to lose some money and of giving someone mobile phone to transact money on the behalf of respondent was the third largest incident (9.2\%). The result of the vast majority is similar to that showed in the literature review obtained by a survey done by Wamuyu (2014) in Kenya. The observation done by a researcher revealed that some mobile money companies who engage in the business of MMT do not give rooms to their customers to make a review of the identities of the person to which the transaction is intended to. However, some customers make this mistake by themselves accidentally by simply of being careless or due to the rushing to accomplish the transaction.

\subsection{Barriers Faced by Mobile Money Users}

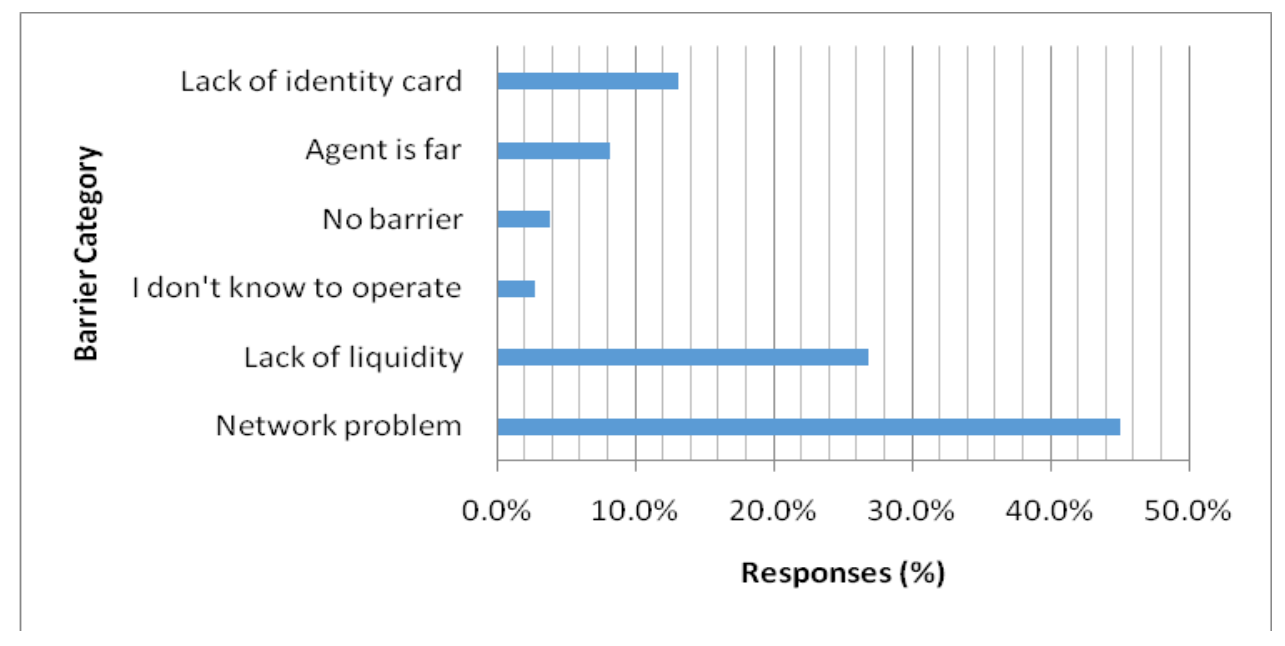

Figure 4. Respondent views on barriers faced by user in MMT 
The second section contained questions that sought to establishes barriers in which mobile users face and the frequencies of occurrences. One question was set to identify types of barriers in MMT, it was multiple responses questions that allowed respondents to mark more than one responses. The responses show that (Figure 4) network problems is the major barrier faced by users during MMT (45.1\%) followed by lack of liquidity by MMS retail agents $(26.9 \%)$ and the third largest barrier is a lack of identity card $(13.2 \%)$ to complete MMT. The results herein contrasting that obtained by Maurer (2011) done in Afghanistan which declared that illiteracy, lack of some people to own mobile phone were important barriers. It also contrasts with that of Dzokoto and Appiah (2012) in Ghana which also observed the illiteracy of the users and government regulations to be major barriers. The issue of illiteracy was also addressed by a study by interMedia (2013) in a survey done in Tanzania. However, lack of liquidity and lack of legal documents to access MMT concur with the study of Maurer (2011) in Afghanistan and that of interMedia (2013) in Tanzania. Though, neither of the studies noted in literature review revealed the network as problems in MMT, but this study evidenced that the dramatic increase of users in MMT in recent years cause the scramble of mobile trafficking signals which then pose a great barrier of network accessibility. This study further observed that the business competition of the mobile money companies and the needs to cover large number of users that subscribed to their services, forced them to register retail agents without a prior and proper verification to ensure that they have enough capital to run the business to avoid the persisted problem of lack of liquidity among them.

This can be observed in the figure 4 above that only $10 \%$ of the respondent agreed that retail agent is far from their premises, which mean $90 \%$ of respondents live closer to these mobile money services.

Table 2. Respondents Views on the Frequency of Facing Barriers in MMT

\begin{tabular}{|l|l|r|r|r|}
\hline \multicolumn{2}{|c|}{ Category } & Frequency & Percent (\%) & Valid Percent (\%) \\
\hline \multirow{2}{*}{ Valid } & Not at all & 16 & 16.0 & 16.0 \\
\cline { 2 - 5 } & Moderate & 62 & 62.0 & 62.0 \\
\hline & $\begin{array}{l}\text { More } \\
\text { frequently }\end{array}$ & 22 & 22.0 & 22.0 \\
\hline & Total & 100 & 100.0 & 100.0 \\
\hline
\end{tabular}

Another question of this section was multiple choice question, it sought to establish the frequency of occurrences of the barriers in MMT and it needed respondents to tick only one response among of three (not at all, moderate, frequently). The results in Table 2 above witness that there are moderate occurrences of barriers in MMT in Tanzania by $62 \%$ and that 
only $22 \%$ experienced barriers more frequently, while $16 \%$ did not face MMT barrier at all. The major barriers mobile money users face is poor network accessibility followed by lack of liquidity, however, few respondent revealed to face barrier more frequently, this evidences that the majority of users which are more than half of the respondents face barriers in moderate rates. The study observed that mobile money companies put some effort to stabilize their network infrastructures in the essence of trying to avoid network barriers in MMT. However, though interMedia (2013) just pointed out the lack of liquidity as a major barrier in MMT in Tanzania, they did not disclose any data to evidence the frequencies of barrier occurrences.

\subsection{Extent of Risks and Barriers Awareness by Mobile Money Users}

This was the last section which targeted to know the level of awareness of mobile money users in MMT. Two questions were set to know the extent to which users can commit risk or expose to barriers unintentionally, all these because of lack of awarenesses while the last question was sought to establish the areas of MMS in which users would like to get training. One question was set to know the extent of the users to operate mobile money application for MMT.

Table 3. Respondents Views on the Awareness of Application of MMT

\begin{tabular}{|l|l|r|r|r|}
\hline \multicolumn{2}{|c|}{ Category } & Frequency & Percent (\%) & Valid Percent (\%) \\
\hline \multirow{2}{*}{ Valid } & Not at all & 7 & 7.0 & 7.0 \\
\hline & Little & 15 & 15.0 & 15.0 \\
\hline & Moderate & 47 & 47.0 & 47.0 \\
\hline & Excellent & 31 & 31.0 & 31.0 \\
\hline
\end{tabular}

The results in Table 3 above indicate that the awareness of the user to operate mobile money application is reasonable in which $47 \%$ of respondents have average understanding, $31 \%$ have excellent understanding while $15 \%$ have a little capability and only $7 \%$ have no idea of MMT at all. Therefore, the extent to which a mobile money user can intentionally commit risks or barrier due to poor understanding of the MMS is minimal because they have a large extent of awareness. The results herein showed a significant distinct with those of Chipchase et al (2011) in Afghanistan, Dzokoto and Appiah (2012) in Ghan, and that of Tanzania done by interMedia (2013) which all addressed that issue of illiteracy faced by mobile money users. This difference of the results are obviously contributed by the concurrent increasing of promotions and advertisement accompanied by regular training done by mobile money 
companies to their users through TV, radio, magazine, flyers and brochures which essentially lead to increase in awareness and level of literacy among the users.

Table 4. Respondents Views on the Awareness of Risks in MMT

\begin{tabular}{|l|l|r|r|r|}
\hline \multicolumn{1}{|c|}{ Category } & & Frequency & Percent (\%) & Valid Percent (\%) \\
\hline \multirow{2}{*}{ Valid } & I don't know & 8 & 8.0 & 8.2 \\
\hline & I know just moderate & 27 & 27.0 & 27.6 \\
\cline { 2 - 5 } & I know it very well & 45 & 45.0 & 45.9 \\
\cline { 2 - 5 } & $\begin{array}{l}\text { I know, but I trust the } \\
\text { person }\end{array}$ & 18 & 18.0 & 18.4 \\
\cline { 2 - 5 } & Total & 98 & 98.0 & 100.0 \\
\hline \multirow{2}{*}{ Missing } & Not answered & 2 & 2.0 & \\
\hline Total & & 100 & 100.0 & \\
\hline
\end{tabular}

The next question on this section was sought to observe the incidence in which respondents can expose themselves to the risk unintentionally due of poor awareness. Table 4 above summarizes the results that a large number of respondents are aware of the risks involved in MMT. While $45 \%$ of all respondents revealed to have very well understanding about the risk involved when someone doing MMT on their behalf, 27\% have an average understanding and only $8 \%$ don't have the understanding at all. The results here support the previous results above (Table 4) that the average number of respondents are literates in such a way that they can identify some factors which expose them to the risks and hence know how to mitigate them. These results emphasise the dissimilarity of the results obtained by the literature pointed above. 


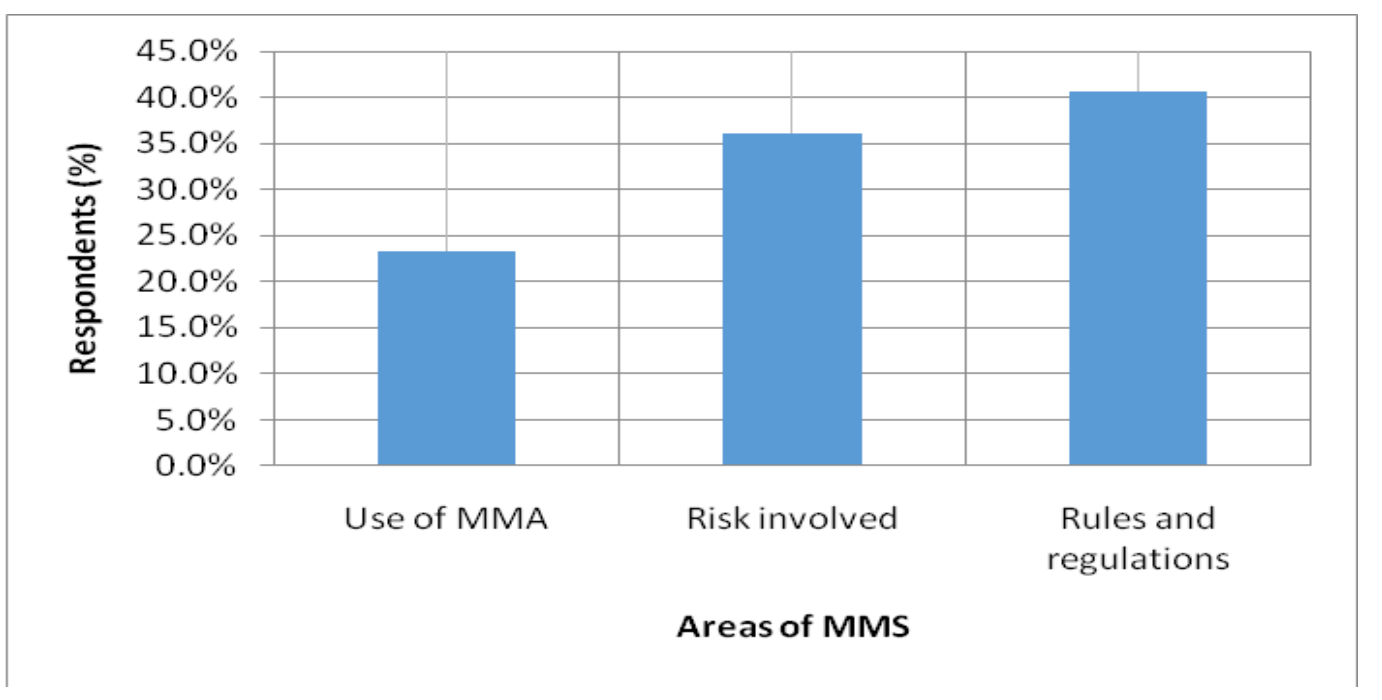

Figure 5. Respondents Views on Areas of MMS Need Awareness

The last question in this section sought to establish the areas of MMS in which respondents eager to learn and get more knowledge. Figure 5 above show the details of the results, that the largest part of respondents need to get education about rules and regulations of MMS, the research results revealed that more than $40 \%$ of the respondents need more awareness in this area, $36.1 \%$ focused more on risk involved in MMS and only that $23.2 \%$ observed the mobile money application to be in consideration. The results imply that regardless of the average awareness of mobile money still there is a need to give education and training to users about rules and regulations as well as risks concerned in MMT. The literature in this study came up with a similar argument, Ally (2014) and Villasoner (2013) assert that MM is sometimes exploited by some crime activities, therefore, rules and regulations are important to a quick move of unbanked to digital financial inclusion. Villasoner furthered emphasized that the regulations should set out should not impede the MMS but should adapt traditional financial systems to combat crimes MM industries in most appropriate ways.

\section{Conclusion and Policy Implications}

Most and common risks of MMT in Tanzania are a loss of password, fake transaction request, and fake money. Most people observed to experience the risk of losing password hence failed to get authentication to access mobile money application to complete transactions. The finding also shows that the incidences of risks to happen were largely caused by mobile money users; they simply exposed themselves in the risking environment, by either being illiterate or lack of awareness. However, the study shows that the problem of risks occurrences is not high, only that average incidence was observed. The study again revealed that although there is the average rate of barriers incidences in MMT, poor network problems seemed to lead, followed by lack of liquidity and lack of legal document to accomplish the transaction. The three mentioned barriers observed to be large hindrances that impede users of MMS in Tanzania. Though, most of the barriers seemed to be caused by MNO or MM 
agents and rarely by users. The study further asserts that the awareness of mobile money users in MMT is reasonable in which nearly half of them have an average understanding that seemed to be adequate for them to operate basic mobile user application as well as the ability to identify risking factors. That means they have the ability to navigate all basic mobile money applications to make most of the transactions like send and receive money, paying the bill etc. However, although few people showed interest to get more knowledge on the uses of mobile money applications, most of them were enthusiastic to get more knowledge on the rules and regulations as well as risks involved in MMT, regardless of their reasonable rate of understanding.

A dramatic use of mobile money service in Tanzania is readily associated with some risks and barriers. The innovation of smartphone and the mobile money software expose MMT readily to cybercrime activities which may include money laundering and financial terrorism. It is obvious that it needs a government attention to prepare special policy, set rules and regulations that can combat all kind and the foreseen risks which are harmful to the economy of Tanzania, to ensure quick move of MMT to a fully digital and financial inclusion.

\section{References}

Ally, A. (2014). 'The prospects and legal challenges posed by M-Payments and M-banking services in Tanzania'. Open University Law Journal, 5(1), 49-57. [Online] Available: www.oulj.net/index.php/ouljpath/article/download/54/45 (March 14, 2015)

Branic, N. (2014). Routine Activity Theory. [Online] Available: https://webfiles.uci.edu/ckubrin/Branic_Routine_Activities_Theory_Entry.pdf?uniq=-321sbd (March 15, 2015)

Chaia, A., Dalal, A., Goland, T., Gonzalez, M. J., Morduch, J., \& Schiff, R. (2010). Half of the world is unbanked. [Online] available: http://www.financialaccess.org/sites/defa ult/files/publications/Half-the-World-is-Unbanked.pdf (December 05, 2014)

Chatain, P., Zerzan, A., Noor, W., Dannaoui, N., \& de Koker, L. (2011). Protecting Mobile Money against Financial Crimes: Global Policy Challenges and Solutions. [Online] Available: http://www.globalinitiative.net/download/financial-crime/global/World\%20Bank\%20-\%20Pr otecting\% 20Mobile\%20Money \%20against\%2 0Financial\%20 Crimes.pdf (March 15, 2015)

Chipchase, J., Lee, P., \& Maurer, B., (2011). Mobile Money: Afghanistan, 6(2), (13). http://dx.doi.org/10.1162/INOV_a_00067

Cohen, E., Lawrence E., Marcus, K., \& Felson, M. K. (2010). Routine Activity Theory. [Online] Availble: http://www.sagepub .com/schram/study/ materials/reference/90851_03.2r.pdf (March 15, 2015)

Crabtree, C. D. (2006). The Interpretivist Paradigm: Assumptions and Beliefs of the Interpretivist Paradigm. [Online] Available: http://www.qualres.org/HomeInte-3516.html (March 16, 2015) 
Cresswell, J. W. (2011). Research Design: Qualitative, Quantitative, and Mixed Methods Approach (3rd ed). Vivek Mehra: New Delhi.

Demirguc-Kunt, A., \& Klapper, L. (2012). Measuring Financial Inclusion: The Global Findex Database. http://dx.doi.org/10.1596/1813-9450-6025

Di Castri, S. (2013). Mobile Money: Enabling Regulatory Solutions. http://dx.doi.org/10.2139/ssrn.2302726

D'orsay, A. E. (2014). What is: Social Constructs. [Online] Available: http://tonidorsay.tumblr.com/post/98671250384/what-is-social-constructs (March 12, 2015)

Dzokoto, V. A., \& Appiah, E. (2012). Making Sense of Mobile Money in Urban Ghana: Personal, Business, Social and Financial Inclusion Prospects. [Online]. http://www.imtfi.uci.edu/files/docs/2014 /dzkoto_final_r eport_feb2014.pdf (March 18, 2015)

Economides, N., \& Jeziorski, P. (2015). Mobile Money in Tanzania. http://dx.doi.org/10.2139/ssrn.2539984

Feinberg, K. (1990). Critical Theory of Technology, 1(5), 17. http://dx.doi.org/10.1080/10455759009358413

Feinberg, K. (2005). Critical Theory of Technology: An Overview. [Online] Available: https://www.sfu.ca/ andrewf/books/critbio.pdf (March 13, 2015)

Financial Action Task Force (FATF) (2013). 'Anti-Money Laundering and Terrorist Financing Measures and Financial Inclusion. [Online] Available: http://www.fatf gafi.org/media/fatf/documents/reports/aml _cft_measures_and_financial_inclusion_2013.pdf (March 15, 2015)

Global eSchool \& Community Innitiative (GESCI) (2012). New Strategies for Science Technology and Innovation. Nairobi: ALICT-GESCI.

GSMA (2014). Sate of the Industry: Mobile Financial Services for the Unbanked. [Online] Available:

http://www.gsma.com/mobilefordevelopment/wp-content/uploads/2015/03/SOTIR_2014.pdf (March 18, 2015)

GSMA (2015). State of the Industry 2014: Mobile Financial Services for the Unbanked [Online] Available: http://www.gsma.com/newsroom/press-release/mobile-money-customers-increased-over-40-p er-cent-100-million-2014/ (November 17, 2015)

InterMedia (2013). Mobile Money in Tanzania: Use, barriers and opportunities. [Online] Available: http://www.intermedia.org/wp-content/uplo ads/FITS_Tanzania_FullReport_final.pdf (February 10, 2015) 
International Telecommunication Union (ITU) (2013). The mobile money revolution Serving the unbanked. [Online] Available: https://itunews.itu.int/ En/4340-The-mobile-money-revolution-BR-Serving-the-unbanked.note.aspx (December 05, 2014)

Krauss, S. E. (2005). 'Research Paradigms and Meaning Making: A Primer. [Online] Available: http://www.nova.edu/ssss/QR/QR10-4/krauss.pdf (March 19, 2015)

Magigi, W. (2015). Research Proposal Development and Report Writing: A Pathway for Success in Higher Learning Institutions. 1st edition. Safi Publishers. Moshi.

Materu-Behitsa, M., \& Diyamett, B. D. (2010). Tanzania ICT Sector Performance Review 2009/2010: Towards Evidence-based ICT Policy and Regulation Volume Two, Policy Paper 11, 201. [Online] Available: http://www.researchictafrica.net/publications/ICT_Sector_Performance_Reviews_2010/Vol\% 202\%20Paper\%2011\%20\%20Tanzania\%20ICT\%20Sector\%20Performance\%20Review\%20 2010.pdf (February 15, 2015)

Merritt, C. (2010). Mobile Money Transfer Services: The Next Phase in the Evolution in Person-to-Person Payments. [Online] Available: https://www.microlinks.org/sites/microlinks/files/resource/files/Mobile\%20Money\%20Transf er\%20Services.pdf (March 15, 2015)

Mokolane, B. J. (2013). 'Evaluating Implementation of the Integrated Development Plan Towards Service Delivery in a Local Municipality. [Online] Available: https://ujdigispace.uj.ac.za/bitstream/h andle/10210/11266 /Mokalane\%20BJ\%202014.pdf?sequence=1 (March 18, 2015)

Mshna, J. A. (2015). Cybercrime: An Empirical Study of its Impact in the Society - A Case Study of Tanzania. [Online] Available: http://www.out.ac.tz/files/documents/HURIA\%20JOURNAL\%20VOL\%2019.pdf (March 18, 2015)

Mutong'wa S. M., Khaemba S. W., \& Mengichi, E. M. (2014). A Comparative Study of Critical Success Factors (Csfs) in Implementation of Mobile Money Transfer Services in Kenya.

[Online] Available: http://www.idpublications.org/wp-content/uploads/2014/08/A-Comparative-Study-of-Critical -Success-Factors-Csfs-in-Implementation-of-Mobile-Money-Transfer-Services-in-Kenya.pdf (March 20, 2011)

National Bureau of Statistics (NBS) (2012). Population and Housing Census: Population Distribution by Administrative Areas. [Online] Available: http://www.tzdpg.or.tz/fileadmin/documents/dpg_internal/dpg_working_groups_clusters/clust er_2/water/WSDP/Background_information/2012_Census_General_Report.pdf (March 21, 2015) 
National Crime Prevention Council (2012). Cybercrimes. [Online] Available: http://www.ncpc.org/resources/files/pdf/internet-safety/13020-Cybercrimes-revSPR.pdf (March 20, 2015)

Nielsen, J. (2014). The Modern Wallet: Mobile Payments Are Making Life Easier. [Online] Availbale: $\quad$ http://www.nielsen.com/us/en/ins $\quad$ ights/new s/2014 /whats-in-your-wallet-mobile-payments-are-making-life-easier.html (December 12, 2014)

Pénicaud, C., \& Katakam, A. (2013). State of the Industry: Mobile Financial Services for the Unbanked. [Online]. Available from: http://www.gsma.c om/mobilefordevelopment/wp-content/uploads/2014/02/SOTIR_2013.pdf (March 12, 2015)

Realini, C. (2011). Securing Mobile Money to deliver on the Promise. [Online]. Available from: http://www.pymnts.com/asse ts/Lydian Journal/L ydianJournalFebTech.pdf (March 15, 2015)

Robins, R. (1995). Database Fundamentals. [Online]. Available: http://www.esp.org/db-fund.pdf [Accessed 12 March 2015].

Rouse, M. (2008). Data analytics (DA) definition. [Online] Available: http://searchdatamanagement.techtarget.com/definition/data-analytics (March 12, 2015)

Senso, N. C., \& Venkatakrishnan, V. (2013). Challenges of mobile-phone money transfer services' market penetration and expansion in Singida District, Tanzania. [Online] Available: http://www.ejisdc.org/ojs2/index.ph p/ejisdc/article/view/1302/530 (March 05, 2015)

Van Der Voordt, T., \& Wendelien, L. (2002). Descriptive Research. [Online] Available: http://www.bk.tudelft.nl/fileadmin/Faculteit/BK/Over_de_faculteit/Afdelingen/Real_Estate_a nd_Housing/Organisatie/Medewerkers_RE_H/Personal_pages/VanderVoordt/General_list/do c/2002-WaysToStudy_Descriptive_research.pdf

Villasener, J. (2013). Smartphones for the Unbanked: How Mobile Money Will Drive Digital Inclusion in Developing Countries [Online] Available: http://www.brookings.edu/research/papers/2013/09/16-smartphones-mobile-money-developin g-countries-villasenor (December 05, 2014)

Wamuyu, P. K. (2014). The Role of Contextual Factors in the Uptake and Continuance of Mobile Money Usage in Kenya [Online] Available: http://www.ejisdc.org/ojs2/index.php/ejisdc/article/view/1302/530 (December 12, 2015).

World Bank (2012). Who are the Unbanked?: Uncovering The Financial Inclusion Gap [Online]

Available: http://siteresources.worldbank.org/EXTGLOBALFIN/Resources/8519638-1332259343991/w orld_bank3_Poster.pdf (December 12, 2014) 


\section{Copyright Disclaimer}

Copyright for this article is retained by the author(s), with first publication rights granted to the journal.

This is an open-access article distributed under the terms and conditions of the Creative Commons Attribution license (http://creativecommons.org/licenses/by/3.0/). 